\title{
Role and implementation of sustainability management control tools: critical aspects in the Italian context
}

Katia Corsi

Economics and Business, University of Sassari, Sassari, Italy, and Brunella Arru

Department of Agriculture, University of Sassari, Sassari, Italy

\begin{abstract}
Purpose - The purpose of this paper is to show the relevance attributed to sustainability management control tools (SMCTs) and their real use. Mainly, this study aims to shed light on the approaches, motivations and difficulties encountered in SMCTs adoption by the most sustainable Italian companies, as well as their effectiveness.

Design/methodology/approach - Using a pre-structured qualitative survey method, the authors grasped information about external and internal dimensions of sustainability management in light of institutional and resource-based view theories. Data are elaborated with two methods: a regime analysis to assess the relevance of SMCTs and a descriptive analysis to investigate the "aim", "which" and "how" of the SMCTs' use by companies listed in sustainability indices.

Findings - Informal SMCTs prevailed over formal ones. There is a discrepancy between attention paid to some tools praised in the literature and their knowledge and use. In addition, a significant gap exists between what is desired and what is achieved in terms of effectiveness. Further, although sustainability management is primarily oriented towards the external perspective, SMCTs can be key to improving both the disclosure and management of sustainability.

Research limitations/implications - The criteria for the selection of the sample resulted in a small number of analysed companies, which allowed us to gain insight into what happens inside the listed Italian companies in the most important sustainability indices. These companies have sustainability-oriented management, which also probably safeguards their advantage linked to inclusion in these indices.

Practical implications - This paper provides food for thought for companies engaged in non-financial disclosure and for those who aim to implement SMCTs. It shows the need to reinforce formal sustainability control tools, also through dissemination of major knowledge about the implementation of these tools, and to encourage sponsorship from top levels of management.

Originality/value - Compared with SMCT research using a theoretical or case study approach, this study uniquely undertakes extensive research on the perceived effectiveness of SMCTs in achieving sustainability goals and the difficulties in implementing them, thereby highlighting a discrepancy between some tools emphasised in the literature and those infrequently used in sustainability-oriented companies.
\end{abstract}

Keywords Sustainability control package, Resource-based theory, Sustainability tools, External and internal perspectives, Qualitative survey

Paper type Research paper

(C) Katia Corsi and Brunella Arru. Published by Emerald Publishing Limited. This article is published under the Creative Commons Attribution (CC BY 4.0) licence. Anyone may reproduce, distribute, translate and create derivative works of this article (for both commercial and non-commercial purposes), subject to full attribution to the original publication and authors. The full terms of this licence may be seen at http://creativecommons.org/licences/by/4.0/legalcode

Funding: The research leading to these results has received funding from the "Fondo di Ateneo di Sassari della ricerca 2019".

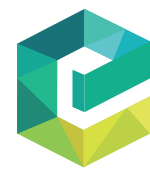

Received 12 February 2019

Revised 21 October 2019 6 July 2020

Accepted 3 September 2020 


\section{AAAJ}

34,9

\section{Introduction}

Sustainability is a multifaceted concept that has evolved significantly since first arising in 1987 in the Brundtland Report, which has been strengthened with the UN 2030 agenda.

Given that business plays an important role in achieving sustainable development (UN Global Compact, 2020), in this work we embrace the concept of sustainability as the need to include social and environmental concerns in decision-making processes and business operations and to integrate and reconcile them with traditional financial aspects in order to ensure the greatest advantages for both companies and the whole society (Graf and Wirl, 2014; Lankoski, 2016; Saviano et al., 2018).

More and more academics and practitioners believe that companies cannot pursue sustainability strategies and sustainability disclosures without collecting and elaborating data and controlling sustainability objectives (Bebbington and Thomson, 2013; Bebbington and Unerman, 2018; Crutzen and Herzig, 2013; Rodríguez-Olalla and Avilés-Palacios, 2017; Wasner and Majchrzak, 2015). Companies need suitable management tools to integrate sustainability issues within decision-making processes, to become more proactive and transparent in their management of sustainability activities and to integrate two business perspectives of sustainability: the traditional external perspective oriented to sustainability disclosure and the internal perspective oriented to sustainability performance improvement (Arjaliès and Mundy, 2013; Maas et al., 2016a).

For These reasons, companies have adopted sustainability management control tools (SMCTs) that, on the one hand, are geared towards measuring and communicating the social, environmental and financial performances needed to improve management, direct employee behaviour and support decision-making processes. On the other hand, they improve the reliability of sustainability disclosures, allowing smoother and more effective communication between the company and outside world, thus facilitating stakeholders engagement.

In this way, SMCTs also allow companies to avoid falling into the trap of "greenwashing" or philanthropic activity or even simple compliance with the law (see the recent Directive 95/ 2014/EU). This moves the sustainability axis from a rhetorical stance to an effective response to increase institutional pressures from many stakeholders (Cresti, 2009; Epstein, 2003; Laufer, 2003; Lyon and Maxwell, 2011; Wijethilake et al., 2017).

Some studies focussed on a single tool, such as the sustainability balanced scorecard (SBSC) (Corsi and Arru, 2018; De Villiers et al., 2016), while others focussed on several control tools (formal and informal), sometimes also as a "package", defined as a sustainability management control package (SMCP) (e.g. Crutzen et al., 2017; Gond et al., 2012; Maas et al., 2016b; Riccaboni and Leone, 2010). To date, however, few empirical studies have focussed on the actual use of SMCTs to develop a corporate sustainability strategy and foster a commitment to sustainability.

This paper focusses on this wave of interest and has two aims. Firstly, it aims to highlight the relevance of SMCTs, considering them by both theoretical and operative perspectives. Research was carried out using a qualitative survey method (Jansen, 2010) among Italian companies included in the most important sustainability indices (defined in this work as sustainability-oriented companies - SOCs). This was in contrast to other studies which have mostly dealt with this matter using a theoretical approach (Gond et al., 2012; Lueg and Radlach, 2016) or case studies (Gunarathne et al., 2016), which are unable to provide a full picture of practices adopted and shared among several companies. For this aim, we adopted a regime analysis method. Afterwards, as our second aim, we analysed the approaches of these companies in using SMCTs, shedding light on the "why", "which" and "how".

This paper makes several contributions to the literature. Firstly, it addresses recent calls for research into the role of management control tools in changing and improving company practices to achieve the Sustainable Development Goals of the United Nations Agenda 2030 (Crutzen et al., 2017; Johnstone, 2019; Wijethilake et al., 2017). By focussing on the role of 
SMCTs within the analysed companies, this study provides insights into the relevance of SMCTs compared to other corporate sustainability dimensions (sustainability department and sustainability background). Secondly, it responds to new requests for research into the use of management control tools to make companies more transparent and more proactive, which are then able to integrate competencies to support the building of sustainability dynamic capabilities (Wijethilake and Ekanayake, 2018). Thirdly, it provides detailed insight into SMCTs adopted by the analysed companies, highlighting the gap between expected and perceived effectiveness as well as the discrepancies between the awareness of some tools lauded in the literature and their actual usage.

The paper is structured as follows. Section 2 reviews previous studies on sustainability perspectives and SMCTs. The research methodology and sample description are illustrated in Section 3. Section 4 presents the results of the research. Section 5 discusses the results, and Section 6 concludes our paper, outlines the implications for practitioners, academics and policymakers and makes recommendations for future research.

\section{Literature review}

Currently, the demand for greater transparency regarding commitment to social and environmental outcomes has become stronger. The sustainability issue in organisations cannot, however, be addressed entirely in the disclosure arena. Organisations must incorporate sustainability values [1] in their business and day-to-day operations, turning them into management practices (Engert et al., 2016). In recent years, academic literature has dealt with the external and internal pressures that push companies toward the development and use of management and control systems to disclose and achieve sustainable objectives (Bowen, 1953; Pondeville et al., 2013; Windolph et al., 2014). According to previous studies (Lueg and Radlach, 2016; Wijethilake; Ekanayake, 2018), we used the institutional theory and resources-based view (RBV) theory to explain the internal and external factors that determine corporate sustainability responses and sustainable management, highlighting the relevance of SMCTs in the sustainability-oriented management that affects their use, as synthesised in Figure 1.

According to the literature, the institutional theory and RBV theory (Wijethilake and Ekanayake, 2018) explain companies' sustainability development patterns linked to (1) different pressures, (2) the prevalent approach and (3) organisation behaviour patterns.

An early contribution by Di Maggio and Powel (1983) points out that companies are subjected to a strong push towards homogenisation (isomorphism) through three mechanisms (Herremans and Nazari, 2016; Wijethilake et al., 2017; Windolph et al., 2014):

(1) Regulative (or coercive) isomorphism, which refers to the explicit regulative processes realised by several subjects that establish rules and supervise their enforcement with sanctions. Companies try to gain social legitimacy by complying with the rules set to guarantee the attention of companies to sustainability;

(2) Normative isomorphism, which is related to the standards and values that influence individuals to act in professional and standardised ways and satisfy social requirements. In recent years, professional networks and corporate sustainability associations have increased to disseminate management practices as well as training and education;

(3) Cognitive (or mimetic) isomorphism, which refers to shared knowledge that can influence how a phenomenon is interpreted. Overall, in uncertain situations, sustainable behaviours can be derived from imitating organisations that exhibit the best practices.

The other widely used theoretical approach (RBV) is more internally oriented. It focusses on a corporation's capability to manage valuable, rare and inimitable corporate resources - which 


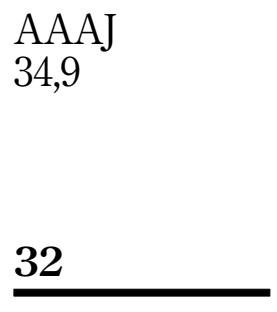

Figure 1.

The visual representation of the literature review

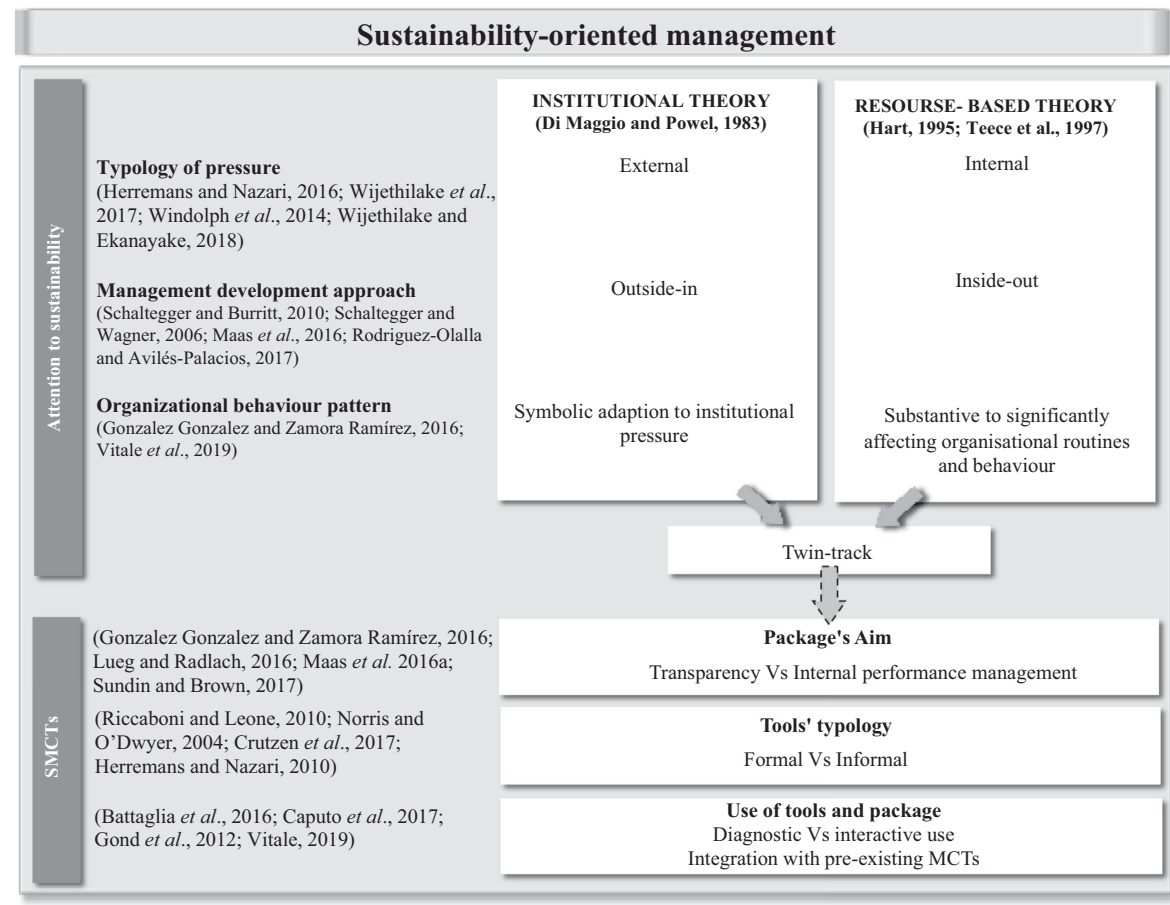

are a complex of assets, organisational processes, attributes, information, knowledge and so on - to develop sustainable competitive advantages (Barney, 1991; Russo and Fouts, 1997). Capabilities become dynamic when they improve the decision-making process, identify opportunities and threats, solve problems and modify existing resources (Barreto, 2010).

Sustainability is understood as a strategic and intangible asset (Lueg and Radlach, 2016), and the inclusion of its value in corporate culture improves the internal capabilities and overall performance of the organisation (Hart, 1995; Russo and Fouts, 1997), fosters sustainability practices at all levels of the organisation, and this, in turn, supports the strategic intent of the firm (Galpin et al., 2015). Companies can respond to resource-based sustainability pressures, implementing proactive sustainability strategies (e.g. pollution prevention, product stewardship strategy, sustainable development strategy), and create dynamic sustainability capabilities (Hart, 1995), which are the changes experienced by companies by integrating, building and reconfiguring internal and external competencies to address their impact on the natural and social environment, converting potential threats into a competitive advantage in quickly changing settings (Teece et al., 1997).

Company responses to external (relating to institutional theory) and internal (relating to RBV) pressures towards sustainability range from improving sustainability disclosures to defining a new strategy and increasing commitment. In particular, the two theoretical approaches may be associated with two main paths of sustainability management development proposed in the literature: "outside-in" and "inside-out" (Maas et al., 2016a; Schaltegger and Burritt, 2010; Schaltegger and Wagner, 2006). The outside-in perspective is mainly driven by external pressures. Companies have to define measurements and accounting systems to collect data and information to comply with norms and answer to external requirements, emphasising accountability to all stakeholders (Gray et al., 2009). Conversely, the inside-out perspective, based on the strategic relevance of sustainability, is 
driven by strategy and commitment to social and environmental issues. It needs accounting and control systems to implement sustainable strategies into operational activities.

According to this twofold view, studies attributed to the outside-in approach have focussed on transparency (a symbolic meaning), aimed at disclosing sustainable results and achieving legitimacy. In contrast, the inside-out approach focusses on performance improvement (a substantive meaning), characterised by a strong commitment to realise sustainable value and adopt effective, sustainable business practices needed to create value for society and avoid sustainability having only a formal meaning (Gonzalez Gonzalez and Zamora Ramírez, 2016).

For companies aimed at having good sustainability disclosure and performances, the two perspectives can complement each other and combine in a more advanced approach to sustainability, called a "twin-track" pattern, in which sustainability management tools respond to both external pressures and the strategic needs of the company (Burritt and Schaltegger, 2010; Gonzalez Gonzalez and Zamora Ramírez, 2016; Vitale et al., 2019). In the Gonzalez Gonzalez and Zamora Ramirez (2016) model, based on a matrix that combines institutional pressures (weak and strong) and adoption patterns (substantive and symbolic), the twin-track approach is characterised by strong institutional pressures and substantive patterns with a strong commitment to sustainable business practices. To date, as far as we know, there are no studies that provide a picture of the importance that companies attribute to the external and internal perspectives in terms of this new integrated vision.

The first aim of this work is to investigate the attention paid to different perspectives of sustainability by Italian SOCs to explain the relevance of SMCTs. These are companies included in the main sustainability indices with undoubted attention to sustainability for reputational aims, but also with sustainability management approaches (Windolph et al., 2014).

Notably, on the one hand, we considered the external perspective of sustainability in terms of disclosure through reports and certifications (defined here as "background in sustainability"). Indeed, disclosure is a pivotal component of any corporate sustainability policy, their "status of responsibility", and is often the first step of integrating sustainability into business management (Wijen, 2014). On the other hand, we considered the internal perspective not only in terms of the attention paid to SMCTs (as a dynamic component of management systems) but also concerning the presence of an internal department for sustainability (as a static component of management system). Eccles et al. (2014) found that, in SOCs, it is highly likely that a separate board subcommittee for sustainability oversight has been formed. Moreover, the composition, the chain of command and the name of the sustainability department can be signals of commitment to and orientation towards sustainability (Hillman and Dalziel, 2003; Ruhnke and Gabriel, 2013; Schaltegger and Hörisch, 2017). These three dimensions (SMCTs, sustainability background and sustainability department) can be viewed as fundamental elements to develop sustainability-oriented management.

From these considerations, the first research question arises:

$R Q 1$. What relevance is attributed to SMCTs by SOCs with respect to the other two dimensions of sustainability-oriented management?

The two theoretical approaches, considered in Figure 1, can help us to explain the aim and the different connotations of SMCTs implemented by companies to manage sustainability in reaction to internal and external pressures.

Sustainability management control can be defined as "the set of tools and practices useful to operationalize sustainable strategies and to ensure a balanced achievement of the economic and social and environmental corporate performance" (Vitale et al., 2019, p. 4).
Sustainability management control tools 
AAAJ

34,9

34

Currently, several studies have adopted a control package approach to investigate different control tools used in companies simultaneously. The concept of a control package is as "an arrangement of independent controls grouped together" (Wijethilake et al., 2017, p. 26). Many scholars (e.g. Ditillo and Lisi, 2014; Guenther et al., 2016; Lueg and Radlach, 2016; Sundin and Brown, 2017) have adopted the Malmi and Brown model (2008) comprising five control typologies (planning, cybernetic controls, administrative controls, cultural controls and compensation and incentives), which is considered a holistic approach and can be used to report sustainability performances, manage sustainability aspects and also influence employee behaviours towards sustainable objectives. The SMCP and sustainability information on which they are based represent, in our framework, the proactive answer to institutional pressures (according to institutional theory) and the instruments to develop sustainable strategies and create sustainability dynamic capabilities (according to RBV theory).

In the Malmi and Brown model (2008), different control tools live together in each company, recalling the consolidated tripartite approach of managerial control focussed on results (planning, cybernetic controls and incentives), actions (procedures and governance) and culture (training, symbols, ethics codes and values) (Merchant, 1985). Informal controls play a pivotal role in influencing employee behaviours and increasing the effectiveness of formal controls (Ouchi, 1979). Informal controls (not only organisational but also social and self-control), based on sustainable values that promote desirable conduct driven by environmental, social and economic concerns (Evans et al., 2017; Rusconi, 2019), sometimes can be more powerful and pervasive than formal ones and, thus, prevail (Perego and Hartmann, 2009; Riccaboni and Leone, 2010).

Many studies have focussed on the influence of formal and informal controls in decisionmaking processes concerning environmental and social aspects as well as employee behaviours. Through the use of a reward system, employees are prompted to buy into sustainability and reinforce their motivation to reach sustainable objective (Dutta et al., 2016; Lueg and Radlach, 2016; Norris and O'Dwyer, 2004). Crutzen et al. (2017) analysed 17 Western European companies included in the Forbes list of the largest joint-stock companies of 2009, identifying several sustainable control tools. They showed a complementary relationship between formal and informal controls, and the results led the authors to think that dominant culture controls could be more suitable for managing corporate sustainability (see also Morsing and Oswald, 2009). Herremans and Nazari (2010) linked the combination of formal and informal controls to the nature of institutional pressures: informal controls are weak when the company is subjected to regulative pressures and tend to strengthen and prevail with cognitive pressures.

Among the sustainability-oriented formal controls, there are single tools that favour alignment between sustainability strategies and control systems. Of those, SBSC is the more investigated (Hansen and Schaltegger, 2017, 2016; Schaltegger and Wagner, 2006). SBSC, which shares many elements with sustainability reporting, is widely suggested to integrate economic, environmental and social concerns into a company's strategy. It allows alignment of external and internal sustainability accounting information and integration of sustainability in the company's everyday operations.

Companies that want to manage sustainability must be aware of the existence of these different SMCTs, since "the awareness of sustainability management tools positively influences the application of sustainability management tools in companies" (Windolph et al., 2014, p. 386).

Currently, research on SMCTs is still in the initial phase, requiring further and more indepth studies on the role of SMCTs in integrating sustainability within company management (Durden, 2008; Herzig et al., 2012) and, more importantly, how they are actually used and implemented. 
Herremans and Nazari (2010) associated formal and informal controls with two methods of using the control tools proposed by Simon (1995): diagnostic and interactive. Formal controls tend to be used in a diagnostic way to determine differences between performance and expectations or standards and to correct employee actions; informal controls are used interactively, providing other information to increase knowledge and focus attention on key goals to support innovation and change.

Nevertheless, the use of these SMCTs also involves a relationship with traditional (or preexisting) management control tools (TMCTs), generally aimed at measuring financial outcomes. This relationship can take place by adapting TMCTs to the new needs (e.g. environmental budgeting) or by integrating SMCTs and TMCTs, which seeks to avoid duplication of costs.

According to Vitale et al. (2019), integration can be handled in two ways: "alignment" of new tools with pre-existing ones or "overlap" of sustainability logic with TMCTs. In the latter, sustainability objectives "may be incrementally added in MCSs, and environmental, social and economic concerns gradually incorporated into SCSs [sustainability control systems] that are growing into more comprehensive systems" (George et al., 2016, p. 200). Therefore, companies look to efficiently integrate various control tools in technical, organisational and cognitive terms (Gond et al., 2012). Technical integration concerns the integration of sustainability control tools into formal control systems, creating an information system that can collect, process and communicate financial, social and environmental information. Organisational integration is concerned with defining roles and structures that can facilitate the adoption of practices for sustainable management. Cognitive integration interprets TMCTs and SMCTs as communication platforms that facilitate interaction and allow for an examination of, and a change in, how actors understand organisational objectives and deal with environmental and social problems.

All of these studies have helped to raise awareness among academics and practitioners on sustainability issues (Schulze et al., 2012), but this has led to different concepts and operationalisations of SMCTs (Lueg and Radlach, 2016), impeding their systematisation and the definition of a general framework on how companies can control sustainability issues. SMCTs need further in-depth analyses to strengthen the link between conceptual literature and empirical studies. This could better support companies in sustainable strategy development, facilitating both sustainability dynamic capabilities - pivotal in achieving and sustaining a competitive advantage - and deployment of SMCTs. Since organisations tend to imitate the "best processes and practices" to improve organisational performance (Seeger, 2006), companies understood as SOCs could represent benchmarks to optimise the implementation of SMCTs.

In light of these considerations, our work aims at obtaining insight on the companies and tasks of sustainability management control by answering the following research question:

$R Q 2$. What are the reasons that lead to SMC adoption, and among the single tools of the "package control", which are known, really used and how are they employed by SOCs to facilitate sustainability management and to ensure their effectiveness?

\section{Research methodology}

\subsection{Data sources}

In this work, we analysed Italian companies listed in sustainability indices such as the Global Compact 100 (GC 100), the Ethibel Sustainability Index (ESI), the Standard Ethics Index and the Dow Jones Sustainability Index (DJSI).

These sustainability indices rank companies using complex scoring that summarises the organisation's social, environmental and sustainability performance. However, researchers 
AAAJ

34,9

hold mixed opinions regarding such indices. On the one hand, they have been subject to methodological criticisms concerning more emphasis on economic performance (Fowler and Hope, 2007) as well as the lack of standardisation, transparency, data availability, quality and credibility (Delmas and Blass, 2010; Drempetic et al., 2019; Windolph, 2011), but ethical questions have also been raised linked to the independence and neutrality of the rating agencies (Clementino and Perkins, 2020; Donker and Zahir, 2008; Eccles and Stroehle, 2018). On the other hand, part of the literature considers them valid instruments for signalling companies' sustainable values, behaviours and performance (Batista and Francisco, 2018; Lassala et al., 2017; Stekelenburg et al., 2015) since they provide "comprehensive, systematised and comparable data for a significant number of publicly listed firms" (Clementino and Perkins, 2020, p. 3). In particular, Windolph et al. (2014) showed that "the application of sustainability management tools is higher in companies which participate and are listed in a corporate sustainability index" (2014, p. 385).

Within the earlier debate, our methodology choice stems from the fact that the companies included in these indices have paid more attention to sustainability, even if may be for reputational purposes. This inclusion represents a more objective criterion than others based on more subjective interpretations, such as thorough content analyses or the analyses of webpages addressing social and environmental issues.

After the selection process [2], a total of 34 Italian firms were selected.

According to Jansen (2010), a qualitative sample could be of small size but should represent the diversity of a topic within the target population (SOCs in this case). In our target population, the selection of companies included in the indices mentioned earlier provided a sufficient, relevant degree of variety to realise the aim of this study.

Research took place in the field for more than five months (from 15 February to 20 July 2018). To get the maximum number of answers, firstly, one or more person(s) in charge of sustainability management at each company were contacted by telephone in order to present the research objective and precisely identify the sustainability department manager in order to send him/her the questionnaire. Secondly, three compilation methods were adopted: (1) researcher-assisted telephone interviews; (2) response via online software (Google Docs survey tool); and (3) response by filling out a document to be scanned.

By 20 July 2018, a total of 20 heads of sustainability departments responded to the questionnaire (all valid), yielding a response rate of $58.82 \%$. Some companies refused to participate in the research on policy grounds. This response rate is close to that obtained in similar research [3] and signals an interest in the aim of the analysis.

\subsection{Research model}

Analysis of SMCTs cannot ignore sustainability-oriented management of companies according to the external and internal perspectives that have emerged from the literature. The role/importance assigned to SMCTs is compared to other fundamental elements of sustainability-oriented management, including the sustainability department (as a structure aimed at supporting sustainable goals) and the background in sustainability linked to disclosure (as the first step towards sustainability management). This comparison allows us to highlight which dimension is favoured and offer considerations on the process of integrating internal and external perspectives. Moving away from the attention paid to sustainability to focus only on SMCTs, the subsequent step analysed the aim of SMCP considering two patterns: external (or symbolic), linked to transparency, compliance and meeting the expectations of external stakeholders; and internal (or substantive), linked to performance improvement, strategy operationalisation and capability development (Gonzalez and Zamora Ramírez, 2016; Maas et al., 2016a).

The next step consisted of examining which formal and informal management control tools were known and used by SOCs to achieve their sustainability objectives, being aware 
that SMCTs implementation is fostered by their knowledge (Windolph et al., 2014). We analyse SMCTs' use to highlight whether they were used in a diagnostic or interactive way (Simons, 1995), and then we moved into a level integration between TMCTs and SMCTs according to Gond et al. (2012) framework.

Finally, mindful that for companies to continue to follow the integration process they must be satisfied with the results already achieved, it becomes important to highlight the SOCs perception of the effectiveness of SMCP and of single tools, the perception of gaps to be filled and constraints encountered in the implementation of SMCTs see Figure 2.

\subsection{Method}

Faced with analysing the approach to SMCTs and gathering data (opinions and impressions) from human subjects (Jenkins, 1985), qualitative research was considered to be the most appropriate technique for this empirical work.

Qualitative research deals with non-numerical information and its phenomenological interpretation to answer "how, where, when and why" questions and to build "a meaningful picture without compromising its richness and dimensionality" (Leung, 2015, p. 324).

In particular, we conducted a pre-structured qualitative survey, which was aimed not at establishing "frequencies, means or other parameters but at determining the diversity of some topic of interest within a given population. This type of survey does not count the number of people with the same characteristic (value of the variable), but it establishes the meaningful variation (relevant dimensions and values) within that population” (Jansen, 2010, p. 3).

The qualitative survey was designed by applying a unidimensional description and downward coding it, allowing us to move towards a lower level of abstraction (Jansen, 2010). This articulation of the main object (sustainability-oriented management), dimensions (sustainability department, sustainability background, SMCTs) and categories is indicated in Figure 3.

The questionnaire was divided into four parts. The first part concerned preliminary data on companies (questions 1-4). The second part was aimed at investigating the sustainability background and "cultural maturity" (questions 5-11), collecting information about how long companies had been disclosing sustainability reports and which standards they followed. In the third part, questions were about the department dedicated to sustainability (questions 12 17), and the last section focussed on SMCTs (questions 18-29). This section first aimed to discover the relevance of SMCTs and then the reasons for SMCP adoption, considering four symbolic aims (improvement of company rating, accountability of sustainability issues, improvement of disclosure reliability and improvement of the information system on
Sustainability management control tools

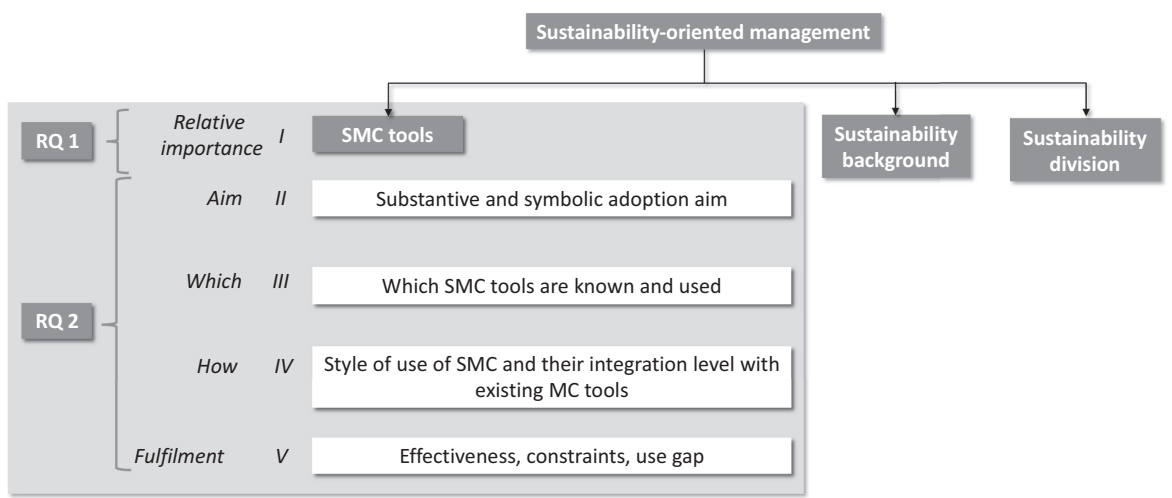

Figure 2. Research model 


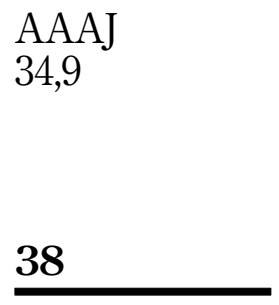

Figure 3.

The organising codes into object, dimensions and categories

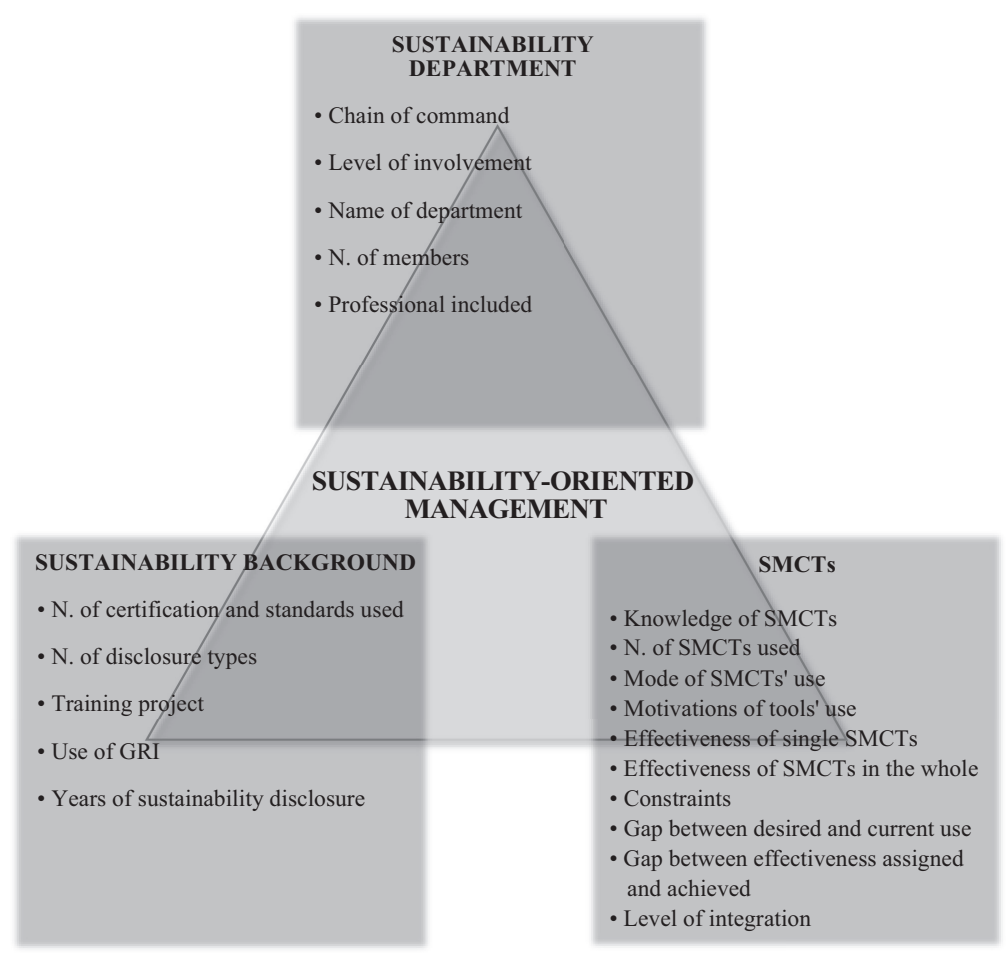

sustainability) and three substantive aims (change management, development of sustainability culture and sustainability implementation in corporate strategy) were proposed.

Secondly, questions were asked about the knowledge of SMCTs and their application in corporate practices. The range of tools supporting sustainability was borrowed from the control package model in which SMCTs coexist. According to the Malmi Brown (2008) and Merchant (1985) model, we used questions on three classes of control tools, that is, the results (such as budget, performance indicators, balanced scorecard, benchmarking and variance analysis, cost accounting and, not least, incentive system), actions (in particular, procedures and auditing) and culture (training, ethical code, symbols/values), and leaving the possibility to indicate additional tools. Further questions were asked about how the SMCTs were used and their integration with pre-existing control tools, as well as the opinions about their effectiveness and implementation problems.

In order to grasp the viewpoints of SOCs about SMCTs, two methodologies were used: multi-criteria analysis (MCA) (first point, Figure 2) and descriptive analysis (points II-V, Figure 2).

MCA is based on a multi-attribute representation of multi-faceted aspects of choice alternatives concerning the various dimensions of corporate sustainability. Among various MCA methods, regime analysis (RA) was chosen. RA is a useful evaluation method to address sustainability problems since it works with both quantitative and qualitative information (Akgün et al., 2012; Nijkamp and Vindigni, 1999). That is why it was previously used to rank different attributes of sustainable development (Akgün et al., 2012; Idda et al., 2002). RA requires defining a priori a distinct set of $i$ th alternatives (sustainability dimensions) and evaluating $j$ th criteria (companies) for all criteria together (Munda et al., 1994). The 
combination of the latter leads to what is called the "regime matrix" to which is added a weight vector to assess the relative dominance of each alternative, expressed as importance rank order. An assessment of the importance attributed to the alternatives is made using pairwise comparisons, and the outranking relationships are built between the alternatives (Nijkamp et al., 1990). Briefly, the mathematical framework of RA builds on two kinds of input data: an impact matrix, which shows the distinct companies' judgements on the importance they have given to all the dimensions of the object (given by the importance attached to each category of each dimension), and a set of (politically determined) weights, that is, the number of indices in which each company is included. RA is an appropriate method here because the nature of the analysis fits our goals perfectly. First, it describes the impact of each dimension of the overall sustainability approach on each company, and second, it describes the performance of each dimension in terms of preferences in qualitative (rank-order) terms.

A descriptive analysis was carried out to identify patterns in the data and describe trends about frequently used tools, methods of use, motivations, appreciations and difficulties of SOCs.

\section{Findings}

Analysing which dimensions of sustainability-oriented management (see Figure 2) are favoured by SOCs allowed us to affirm a propensity for the outside-in perspective.

In response to RQ1, the impact matrix shows that $65 \%$ of companies attributed to the dimension of "background in sustainability" (D1) an importance greater than or equal to that of the other two dimensions, sustainability department (D2) and SMCTs (D3) (see Table 1).

Analysis of the preferences among alternatives (the $c_{i^{\prime}}$ index; see Table A4 of Appendix) shows also that the SMCTs were preferred over the structural dimension of the sustainability department.

Finally, the ranking of preferences among all alternatives (the $C_{i}$ index, see Table A5 of Appendix) shows that "background in sustainability", that is, sustainability disclosure through reports and certifications, was the most important aspect in SOCs (ranking 0.76). Among the companies, $60 \%$ were very familiar with non-financial disclosure, having done it for over ten years, whereas the remaining $40 \%$ had been doing it for about four years, maybe to be compliant with the EU Directive issued precisely four years ago (95/2014) [4]. SMCTs only took the second position (ranking 0.47 ), while the sustainability department had a 0.27 ranking.

Regarding this last dimension, it was present in 19 companies, while only one had a nonformalised structure for sustainability management, which was represented by a working group with several members from different professional cultures. Since setting up a sustainability department is seen as a proxy for better integration of sustainability matters in the company (Ruhnke and Gabriel, 2013), and all companies had it, we are led to confirm that these firms are probably amongst the best Italian firms in terms of sustainability. This department generally used canonical denominations such as sustainability and corporate social responsibility (CSR). For three companies, the name of the department dedicated to sustainability explicitly evoked external or institutional relations (such as external relations

\begin{tabular}{|c|c|c|c|c|c|c|c|c|c|c|c|c|c|c|c|c|c|c|c|c|}
\hline \multirow{2}{*}{$\begin{array}{l}\text { Alternatives } \\
\text { (dimensions of } \\
\text { object) }\end{array}$} & \multicolumn{20}{|c|}{ Criteria (companies) } \\
\hline & 1 & 2 & 3 & 4 & 5 & 6 & 7 & 8 & 9 & 10 & 11 & 12 & 13 & 14 & 15 & 16 & 17 & 18 & 19 & \\
\hline D1 & 4 & 4 & 4 & 1 & 2 & 3 & 3 & 5 & 1 & 5 & 5 & 3 & 3 & 3 & 3 & 5 & 5 & 5 & 4 & \\
\hline D2 & 3 & 2 & 4 & 2 & 1 & 4 & 3 & 3 & 1 & 1 & 3 & 2 & 2 & 3 & 2 & 3 & 4 & 5 & 3 & \\
\hline D3 & 4 & 3 & 5 & 3 & 2 & 4 & 3 & 2 & 1 & 5 & 3 & 2 & 4 & 5 & 3 & 3 & 4 & 4 & 5 & \\
\hline
\end{tabular}

Sustainability management control tools 
AAAJ 34,9

office). In hierarchical terms, almost all companies had a sustainability department that depended on another one dealing with communications (such as investor relations, marketing, communication, etc.). The department had a medium to small and extremely varied composition, involving different competencies (Burritt and Schaltegger, 2001).

In analysing the details of SMCTs (RQ2), firstly we consider the aim of SMCP (point II, Figure 2).

The findings showed that almost all companies (90\%) stated they implemented SMCP for reasons closely linked to integrating sustainability into corporate strategy and developing a sustainability culture. The other substantive aim linked to facilitating change management seems decidedly secondary, being indicated by only $50 \%$ of SOCs.

Regarding symbolic aims, $80 \%$ of the SOCs attributed to SMCP the ability to improve the rating of the company. Another aim was linked to increasing accountability concerning environmental and social issues $(75 \%)$, followed by strengthening the accounting information system $(70 \%)$, which provides and elaborates information about sustainability issues and improves disclosure reliability $(60 \%)$.

These results show that, although the analysis of sustainability-oriented management of SOCs indicates the companies' higher predisposition towards the external perspective (Appendix, Table A5), they appeared to be interested in using SMCP in the first place to respond to internal pressures linked to the creation of an organisational culture that fosters the sustainability strategy. Moreover, except for one company, all companies indicated both symbolic and substantive motivations.

The analysis of SMCTs' knowledge (point III, Figure 2) shows that the most known tools were benchmarking, training and incentive systems. The latter, together with procedures and ethics codes, were the tools selected with "high knowledge". Surprisingly, only half of the companies said they knew, at various levels, three tools related to the control of results, that is, cost accounting, variance analysis and SBSC.

The findings regarding SMCTs' use showed companies recognising sustainability management can be addressed by sharing values and beliefs present in the organisational environment. Almost all companies $(n=19)$ widely used informal control tools that act on corporate culture, such as training on sustainability issues, codes of ethics $(n=18)$ and continuous education $(n=16)$. Less important was the use of symbols $(n=8)$ to promote the company's sustainability goals. Formal tools oriented towards controlling actions by defining specific procedures and auditing activities were adopted by almost all companies $(n=19$ and 18). Among the formal tools used to control results, benchmarking, performance indicators and budget systems prevailed ( $n=18,17$ and 16, respectively). Additionally, the incentive system, used to focus executives' efforts on sustainability aspects, was quite important $(n=17)$. Conversely, the SBSC, although it is one of the most known SMCTs and is more effective at integrating sustainability within company management (Hansen and Schaltegger, 2016), did not achieve consensus. Moreover, among the ten companies that claimed to know the SBSC (of which only seven claimed to have high knowledge), only six companies said they used it. The other results, control tools of cost accounting and variance analysis, played a much smaller role in sustainability management ( $n=10$ and 9 , respectively).

Regarding the timing of implementation, except for three companies, they all claimed to have spent more than 18 months implementing the tools.

The analysis of how SMCTs are used (point IV, Figure 2) showed that the more traditional controls founded on results and actions had two purposes: diagnostic, aimed at aligning employees' behaviours to company objectives; and interactive, aimed at reaching strategic objectives and supporting adequate changes. Concerning the SBSC, $50 \%$ of the companies that used it $(n=6)$ reported both a diagnostic and an interactive purpose, while two gave it only an interactive role. The incentive tool, on the one hand, was used by $50 \%$ of companies in a diagnostic and interactive way; the other two companies used it exclusively as a tool to 
increase knowledge and draw attention to the key objectives of sustainability. Moreover, regarding the cultural controls, the results were heterogeneous: in few cases these tools were exclusively used in a diagnostic or interactive way; in most cases, they were used in both ways (continuous education, $67 \%$; training, $56 \%$; symbols, $50 \%$; ethics code, $59 \%$ ).

Another concern was about how SMCP was integrated (technically, organisationally, cognitively) with pre-existing control systems. The companies seemed able to realise the three forms of integration (since they gave a high average score, on a scale of $1-7$, to all integration forms), although they focussed more on the cognitive form (mean score greater than 5).

The findings from the last part of the survey (point IV, Figure 2) showed that companies were generally satisfied with the effectiveness of these tools in directing employee behaviours towards sustainability objectives (average score ranging from 4.4 to 6.2). The companies revealed more satisfaction with cultural control tools (continuous education and training, with an average score of 5.9) and incentive systems (average score, 6.2). The effectiveness of instruments related to the controls of actions was in second place (average score: procedures, 5.2; sustainability audit, 5.1); the control of results showed overall the least satisfaction (average score: variance analysis, 5.3; balanced scorecard, 5.3; indicators, 5.2; benchmarking, 4.9; cost accounting, 4.8; budget, 4.4). A high level of company satisfaction was shown for the SMCP in terms of its ability to guide the business towards goals of sustainability development. The average value was 5.2 out of a possible 7 ; no company reported a value lower than 4.

Despite these encouraging results, companies understood that they still had to work to achieve the levels of efficiency attributed to SMCP. As shown in Figure 4, there was a gap between the level of achieved effectiveness and the level of effectiveness that companies assigned to SMCTs in guiding them towards achieving their sustainability objectives [5]. Indeed, for only one company no gap was observed between achieved and assigned effectiveness; meanwhile, five companies exhibited a gap of less than $25 \%$, and six companies reported a discrepancy of more than $50 \%$.

The companies were explicitly asked about the level of the gap between current and desired use of SMCP. The results showed that, on average, this gap was still substantial: the average value was 3.5 out of a possible 7 ; only five companies reported a very narrow gap (score ranging from 1 to 2). The need to fill this gap for many companies was particularly prompted by the recent request for non-financial disclosure (EU Directive 95/2014), which requires the disclosure of environmental and social information, including management information, such as indicators used and risks identified and managed [6].

The wide gap between the current and desired use of SMCTs is also linked to some constraints (such as organisational culture, automation of processes, top management sponsorship and budget) in implementing and using SMCTs.

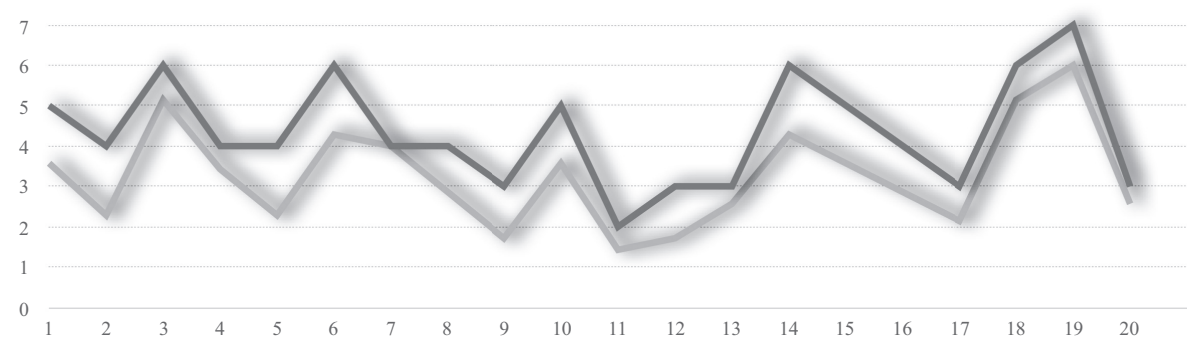

- Level of effectiveness achieved _ - Effectiveness in leading the company towards the company sustainable development
Sustainability management control tools
Figure 4.

Gap between effectiveness assigned and achieved by SMCP 
AAAJ

34,9

42

Finally, it seems that the examined companies had not encountered particular obstacles to implementing and using SMCTs. Among the possible obstacles, the most recorded were the cost of these tools (eight companies) and the difficulty in measuring social and environmental aspects (six companies), because of the qualitative nature of their impact. Four companies reported a lack of support from leaders, although sponsorship from top management was notoriously one of the main incentives for the effectiveness of change management.

\section{Discussion and conclusion}

Nowadays, companies increasingly feel internal and external pressures that push them to go down the path of sustainability and to adopt adequate sustainability management. Following the institutional and RBV theories, this article had two objectives. First, it aimed to investigate the sustainability management of Italian SOCs, highlighting the relevance of SMCTs. Second, this paper aimed at investigating the companies' reasons to adopt SMCP, highlighting the real use of SMCTs in the business context, as well as their effectiveness, constraints and use gap.

Concerning the first aim, RA findings showed that companies paid more attention to disclosure, and the process of translating sustainability values into practice through SMCTs assumed a secondary role compared to the external dimension of sustainability.

Company disclosure practices are seen as pivotal inasmuch they allow the companies to demonstrate "they do things as they should be done" and, thus, legitimise their presence in the market and, in our case, in the sustainable rating indices (Maas et al., 2016a; Morioka and de Carvalho, 2016).

Going into detail, the sustainability background dimension can be explained in light of the three types of isomorphisms in institutional theory. Firstly, given that all companies stated they were using the GRI, this highlights the power of the normative isomorphism. Secondly, the coercive isomorphism was also decisive because of the pressure exercised by the European Commission with Directive 95/2014/EU. It pushes several companies to start reporting social and environmental information in recent years to prepare themselves for the EU Directive application. Thirdly, $60 \%$ of companies communicated their sustainability for about ten years, that is, after the financial crisis of 2007-09. Against this backdrop, companies have attempted to create value and gain trust in a situation of uncertainty, and they may have embraced the widespread thought that demonstrating a visible and authentic commitment to sustainability is important for the future success of their company (Lacy et al., 2010); this behaviour is consistent with mimetic isomorphism.

The presence of a sustainability department in companies can be seen in the light of the RBV theory. This department can contribute to reaching competitive advantages because it can be seen as an inimitable resource. In the division, the skills and abilities of managers integrate and recombine themselves to create new strategic value, and it shows substantive empowerment towards sustainability (not just formal interest pushed by reputational aim).

The findings also showed that companies understood the importance of having a sustainability department, recognising that bundling expertise in a specific department supports development of the necessary know-how for integrating sustainability in corporate strategic and operational planning (Ruhnke and Gabriel, 2013) and for pursuing positive, sustainable performance (Eccles et al., 2014). The sustainability department appeared as a proactive, strategic response to internal sustainability pressures aimed at achieving a sustainable competitive advantage through the generation of dynamic capabilities, which are the result of the work of a resource team (Grant, 1995) according to RBV theory.

At the same time, as the names of sustainability departments referred to institutional or public relations, and they, usually, hierarchically depended on another department that deals 
with communications, we are led to think that such a department can also be used to inform on "good corporate citizenship" and respond to external pressures (Ruhnke and Gabriel, 2013; Schaltegger and Hörisch, 2017). This fact also raises questions regarding the degree of autonomy in the decision-making process of the sustainability department.

Strong SOCs' attention to the external perspective is matched by the secondary importance attributed to SMCTs: it can suggest the persistence of insufficient considerations and inadequate applications of SMCTs (Guenther et al., 2016; Wasner and Majchrzak, 2015). These data may derive from the fact that the limited and fragmented previous research on SMCTs (Maas et al., 2016a) did not favour the development of shared knowledge about their pivotal role and the process of imitating best practices (which can also reduce SMCTs implementation time) or from some constraints highlighted by the respondent companies such as the high implementation costs.

Bringing attention to the SMCTs, this paper firstly investigated the aims of SMCP adoption.

The symbolic adoption aim of SMCP emerged strongly from the companies' adaptation to institutional pressure to obtain legitimacy through the improvement of sustainability rating indices (for $80 \%$ of the companies). This fact can be affected by the choice of sample and requires some specifications. First, sustainability indices generally require specific sustainability management approaches and tools to improve sustainable performances (Windolph et al., 2014). Second, companies listed in sustainability indices can experience coercive pressures from a "lock-in" situation because loss of this status would signal a worsening sustainability performance or reputational loss (Orsato et al., 2015). Therefore, SOCs can use SMCP to guarantee inclusion in the sustainability indices and to gain a reputational advantage.

Additionally noteworthy is that few companies have indicated the symbolic aim of improving the reliability of information communicated to the outside. However, some scholars consider SMCP is pivotal to ensure that information produced and communicated is reliable (Lackmann et al., 2012). Maybe SOCs are satisfied with their level of disclosure quality, or in a cost-benefit analysis they judge SMCP implementation as too expensive. This finding can be read in light of institutional theory.

Normative pressure to adopt behaviour consistent with societal obligation and expectations is not strong enough to induce managers to spend money and time in implementing an appropriate SMCP for improving the reliability of sustainability information. Moreover, in the context of mimetic isomorphism, as "managers are concerned to 'fit in' and to do what has been shaped as "normal" (Bebbington et al., 2009, p. 594), this finding raises questions about the shared knowledge of the sustainability disclosure purpose. It leaves room for theories that see corporate sustainability only as an aesthetic action. Finally, in light of the coercive pressure exerted by Directive 2014/95/EU, which requires disclosure of non-financial information certificated by auditing firms, companies will soon have to pay more attention to the reliability of information and equip themselves with SMCP to manage and measure sustainability. In this regard, the results showed that $75 \%$ of companies reported they had a medium to high gap between the current and desired level of SMCP use and also felt the need to fill this gap to be compliant with Directive 2014/95/EU.

Substantive adoption of SMCP is evident: $90 \%$ of companies said they wanted to use the SMCP to develop a sustainability culture and include sustainability values in company strategy. This finding can be understood in light of the RBV theory that sees corporate sustainability culture as crucial to obtain support from across the entire organisation to the strategic intent of the firm (Galpin et al., 2015). Surprisingly, only half of the companies found the SMCP useful in change management; therefore, they do not consider it particularly suitable for managing people in the transition towards the sustainability approach, or this transition is not well defined. 
AAAJ

34,9

Conclusively, an important point is that "the definition of sustainability management tools is influenced both by the company's management commitment and the external pressures of stakeholder and institutions" (Vitale et al., 2019, p. 5). Findings show that 19 out of 20 companies indicated both symbolic and substantive SMCP adoption aims (Gonzalez Gonzalez and Zamora Ramírez, 2016). This finding is a signal that, although the RA showed that SOCs primarily focussed on disclosure for adapting to institutional pressures, companies are using SMCP as a proactive strategy to respond to both strong external pressure and substantive pattern, heading towards a twin-track approach (Burritt and Schaltegger, 2010; Gonzalez Gonzalez and Zamora Ramírez, 2016; Vitale et al., 2019).

Concerning which tools of the control package are used by companies, the findings showed that formal and informal controls worked together, and generally informal controls prevailed. In accordance with Crutzen et al. (2017), it appears companies think cultural controls can be more appropriate for managing corporate sustainability, raising some considerations in light of the two considered theories.

According to the RBV, by acting on informal controls, the organisational culture, as an intangible resource, could be strengthened and turned into a repository of knowledge (Lemon and Sahota, 2004). Its development, compliant with the history, context and strategy of the company, is crucial to building a sustainable competitive advantage, to disseminate information and to create management commitment that represents pivotal drivers of sustainability responsiveness (Cezarino et al., 2019).

Secondly, according to institutional theory, Herremans and Nazari's framework (2016) shows that informal controls are stronger in the presence of cognitive pressures than regulative ones. Increased attention paid to informal SMCTs can be a signal that SOCs feel cognitive pressure more than regulative pressure, and they are being pushed to adopt a management model based on sustainability values.

Regarding formal control tools, the findings showed that few companies knew the three tools related to the control of results: cost accounting, variance analysis and the SBSC. Therefore, it is a natural consequence that few companies used such tools. Concerning the SBSC, this finding contrasts with the notable importance given to it in the literature, as it is considered as a tool to improve company performance and sustainability management. Previous studies showed an increasing number of companies oriented towards implementing the SBSC, although they still encountered limits in implementation (Hristov et al., 2019). There is likely insufficient normative pressure: there are still few institutions or professional networks that carry out training activities on SBSC and other new sustainability tools (Bebbington and Unerman, 2018; Windolph et al., 2014), letting cognitive pressures prevail, as we said earlier, according to Herremans and Nazari's model. Because of this, it seems necessary to bring to light more successful SBSC applications using case studies that allow sharing advantages, critical issues and implementation methods of this tool.

Among the tools of control package, incentive systems are widely used by SOCs because they are effective to promote sustainability commitment at all company levels (Epstein and Buhovac, 2014). This can be a good signal that pushes us to think we are dealing with SOCs since our sample used this effective tool, although according to some scholars it is not widely used for achieving sustainability targets (Eccles et al., 2014; Lueg and Radlach, 2016). We think that use of this tool will increase to support sustainability in the business context, as the incentive system linked to sustainable objectives can guide employees and managers to adopt sustainable behaviours and solutions (García-Sanchez et al., 2019).

Concerning the way SMCTs are used (Simons, 1995), companies showed that formal control tools had a double purpose: diagnostic and interactive. Among the formal tools, a noteworthy fact concerns the style of SBSC use, given that two companies out of six considered this tool useful only in the diagnostic way; in contrast, one company used the SBSC only in an interactive way. This could be a signal that, although several scholars 
consider this tool as the best to realise sustainable development (Caraiani et al., 2015; Corsi and Arru, 2018), not all companies believe that the SBSC can support alignment of the organisation with the sustainable strategy and at the same time control and communicate it. This confirms the need to disseminate widespread knowledge about the implementation of this tool.

Most companies interpreted culture controls as tools capable of accomplishing both diagnostic and interactive purposes. An interesting fact is that two companies claimed to use a system of incentives only for interactive purposes to conduct dialogues within the organisation and communicate critical strategic aspects on which employees should focus more. This coexistence of two ways of using the same tool does not seem to confirm the associations between formal control tools and diagnostic use as well as between informal control tools and interactive use (Herremans and Nazari, 2016; Simons, 1995).

Investigation into the type of integration between pre-existing tools and SMCTs (Gond et al., 2012) showed that the three perspectives of interest (technical, organisational and cognitive) tended to be mutually connected, although integration at the cognitive level was appreciated to a greater extent. The latter aims at creating common know-how and a corporate culture that both favours the effective introduction of sustainability in business management and influences the behaviour of employees towards environmental and social objectives. Once again, it emerges that companies are looking for a sustainable competitive advantage also through the development of knowledge.

Companies declared themselves satisfied with the entire set of tools. In particular, they were very satisfied with the tools used to control culture, especially the incentive system, as they allowed alignment of employee behaviour towards sustainability objectives. The controls based on actions and results are, respectively, at the second and third levels. In this regard, SOCs' propensity to use informal tools is justified. However, to date, there is a significant discrepancy between the level of effectiveness (in supporting a company in achieving its sustainability goals) ascribed to SMCTs and that currently achieved [6]. This discrepancy can be understood as the companies' awareness about both the potential of SMCTs to achieve sustainability goals and the need for more considerable efforts in using them in response to increasing external pressures to achieve a sustainable advantage.

Cost and issues of measurement of social and environmental aspects were the biggest difficulties encountered by companies in implementing and managing SMCTs. It was particularly significant that $20 \%$ of companies declared the lack of sponsorship by top management as "key to the implementation of sustainability-focused strategic priorities" (Wijethilake and Ekanayake, 2018, p. 143). Top management is the best messenger for communicating reasons for change, legitimising the actions put in place to support change within the organisation and making clear the risks and cost of not changing. The lack of managerial support in the implementation of SMCTs can invalidate the sustainability department's efforts to equip the company with tools capable of measuring and managing sustainability and communicating clear and transparent information to external stakeholders.

\section{Final remarks and implications}

This work, showing the practices of SOCs, provides food for thought for companies engaged in non-financial disclosure, consequently measuring and monitoring the outcomes of environmental and social policies and practices. The satisfaction demonstrated in the use of SMCP, although it is not yet optimally used, suggests that the efforts in implementing and using the control tools are rewarded.

This work can be useful for both practitioners who aim to implement SMCTs - creating greater awareness of their contribution to orient management towards the sustainability path- 
and companies that have already implemented SMCTs - recalling some pivotal elements, such as the role of top management sponsorship.

Several implications for academics can be raised based on our work. First, there is discrepancy between the significant (and perhaps fashionable) attention given to some SMCTs in the literature and their actual use by companies. For example, SBSC is not only rarely used but is also not well known. It is probably necessary to focus more on practical aspects that could lead to members of professional networks implementing these tools and consequently sharing the experience and pushing the spread of SMCTs. Second, the prevalent use of informal controls and the apparent difficulty in measuring non-monetary aspects suggest that more studies are needed to support companies in the implementation of formal SMCTs. Third, this work highlights the importance attributed to cultural controls that can be useful to create sustainability dynamic capabilities and incentive systems that are able to push employees to reach sustainable objectives and reinforce their motivation.

Finally, although the regime analysis shows a higher propensity for the outside-in perspective, the findings show companies used the SMCTs to move towards a twin-track approach. This can stimulate the efforts of scholars to create models of management control in which sustainability integration is realised not only as an "overlap" of sustainability logic to traditional controls but also as an "alignment" process, looking for a profitable interaction between different sustainability-oriented tools (Vitale et al., 2019).

This work could also have political implications deriving from the weight given by companies to the new European law. Coercive pressure may not be sufficiently incisive in inducing companies to adopt the suitable tools to measure and manage social and environmental aspects, which can make sustainability disclosure more effective and reliable (considering the few companies that indicated the symbolic aim of SMCTs in improving disclosure).

A few limitations need to be taken into consideration when interpreting the results. Firstly, this analysis is exploratory and focusses on SOCs included in the most important sustainability indices. These are all large companies, while small and medium companies, equally interested in sustainability, may know and use different management tools because they have different structures, resources and capacities and probably feel less institutional pressure towards sustainability (Wasner and Majchrzak, 2015). Secondly, the applied selection criteria allowed a small number of companies. This prevented us from obtaining a general abstraction from an inductive approach because the results derived from doing so do not assume any statistical significance. However, the choice of the sample was dictated by the desire to take a snapshot as truthful as possible (also using regime analysis) of what happens inside SOCs in Italy. It cannot be ruled out, however, that the criteria adopted for the sample may have selected companies with greater external perspectives to sustainability. Inclusion in the indices may represent a reputational advantage so that companies pay attention to sustainability mainly in order to seek to safeguard this advantage, also implementing SMCTs. Third, data collection was based on interviews with the chairmen of the selected companies' sustainability departments. Therefore, the point of view of managers involved in the sustainability department or further business functions is not considered.

Based on this work, future research can be conducted to investigate (1) the differences in motivation, knowledge, use and integration of SMCTs between sectors and dimensions of companies and countries; (2) differences between listed and unlisted companies in the sustainability indices; (3) successful cases in the implementation of SMCTs to provide indications for companies on how to address this new topic; and (4) integration and interaction between accounting, control and reporting also in light of new norms (see the application of EU/dir. 95/2014) and of future institutional pressures that will derive from current and increasing attention to environmental and social issues by governments and citizens. 


\section{Notes}

1. Sustainability values are the cognition of desirable conduct (Rokeach, 1973) that is driven by environmental, social and economic concerns such as footprint reduction, poverty alleviation, fair distribution, waste reduction and transparency and their associated business strategies understood as clean technology, sustainability vision, pollution prevention and product stewardship (Evans et al., 2017, p. 4).

2. Inclusion in the sample was determined as follows: (1) companies in at least one of the indicated indices were included; (2) controlled companies whose aspects of sustainability are directly managed and disclosed by the parent company were excluded; (3) suspended companies were excluded; (4) recently merged companies, whose approaches and procedures for the management of sustainability must be redesigned and implemented, were excluded.

3. The survey conducted by Windolph et al. (2014) showed a response rate of $25.8 \%$, representing 31 companies. Crutzen et al. (2017), starting with a sample of 555 European companies included in the Forbes 2009 list of the largest operating companies and after applying some selective criteria that reduced the sample to 211 companies, selected only one-third of the companies by random criteria, receiving 17 responses.

4. Directive 2014/95/EU on disclosure of non-financial and diversity information (NFI) imposes, from 2017 onwards, on large companies (exceeding 500 employees) a series of social, environmental and governance statements. The NFI includes: (1) a brief description of the undertaking's business model; (2) a description of the sustainable policies pursued; (3) the outcome of those policies; (4) the principal risks related to those policies; and (5) non-financial key performance indicators relevant to the particular business.

5. The index construction methodology $(\mathrm{Gf} \%)$ is provided in the Table A1 of Appendix.

6. Below, some significant responses from companies:

"The complexity of the company's structure and organisation and the culture of the management are arguments that create difficulties in the full integration of the SMCTs in the traditionally adopted instruments. We need to automate some processes to be able to concentrate on the evolution of CSR required by objectives such as the Sustainable Development Goals".

"Tools are there, but they will not bring full results if they are not recognised, within the company, as relevant to drive and monitor performance. Top management endorsement and commitment can gradually change the managerial culture and the use of tools".

"I would like to push wave [sic] on some instruments, but from time to time, it is difficult to obtain a green light due to budget constraints".

\section{References}

Akgün, A.A., Van Leeuwen, E. and Nijkamp, P. (2012), "A multi-actor multi-criteria scenario analysis of regional sustainable resource policy”, Ecological Economics, Vol. 78, pp. 19-28.

Arjaliès, D.L. and Mundy, J. (2013), "The use of management control systems to manage CSR strategy: a levers of control perspective", Management Accounting Research, Vol. 24, pp. 284-300.

Barney, J. (1991), "Firm resources and sustained competitive advantage", Journal of Management, Vol. 17, pp. 99-120.

Barreto, I. (2010), "Dynamic capabilities: a review of past research and an agenda for the future", Journal of Management, Vol. 36, pp. 256-280.

Batista, A.A.D.S. and Francisco, A.C.D. (2018), "Organizational sustainability practices: a study of the firms listed by the corporate sustainability index", Sustainability, Vol. 10, p. 226.

Bebbington, J. and Thomson, I. (2013), "Sustainable development, management and accounting: boundary crossing”, Management Accounting Research, Vol. 4, pp. 277-283.

Bebbington, J. and Unerman, J. (2018), "Achieving the united Nations sustainable development goals: an enabling role for accounting research", Accounting, Auditing and Accountability Journal, Vol. 31, pp. 2-24.

Sustainability management control tools 
AAAJ

34,9

Bebbington, J., Higgins, C. and Frame, B. (2009), "Initiating sustainable development reporting: evidence from New Zealand”, Accounting, Auditing and Accountability Journal, Vol. 22, pp. 588-625.

Bowen, H.R. (1953), Social Responsibilities of the Businessman, Harper and Row, New York, NY.

Burritt, R. and Schaltegger, S. (2001), "Eco-efficiency in corporate budgeting", Environmental Management and Health, Vol. 12, pp. 158-174.

Burritt, R.L. and Schaltegger, S. (2010), "Sustainability accounting and reporting: fad or trend?", Accounting, Auditing and Accountability Journal, Vol. 23, pp. 829-846.

Caraiani, C., Lungu, C.L. and Cornelia, D. (2015), "Green accounting initiatives and strategies for sustainable development”, IGI Global, pp. 114-139.

Cezarino, L.O., Alves, M.F.R., Caldana, A.C.F. and Liboni, L.B. (2019), "Dynamic capabilities for sustainability: revealing the systemic key factors", Systemic Practice and Action Research, Vol. 32, pp. 93-112.

Clementino, E. and Perkins, R. (2020), "How do companies respond to environmental, social and governance (ESG) ratings? Evidence from Italy", Journal of Business Ethics, pp. 1-19.

Corsi, K. and Arru, B. (2018), "Exploring the effects of sustainability on accounting information systems: the role of SBSC", Network, Smart and Open, Springer, Cham, pp. 235-255.

Cresti, E. (2009), Sustainability Management Control Systems: Towards A Socially Responsible Planning and Control Framework, IAAER, Munich.

Crutzen, N. and Herzig, C. (2013), "A review of the empirical research in management control, strategy and sustainability", Accounting and Control for Sustainability, Emerald Group Publishing, Bingley, pp. 165-195.

Crutzen, N., Zvezdov, D. and Schaltegger, S. (2017), "Sustainability and management control exploring and theorizing control patterns in large European firms", Journal of Cleaner Production, Vol. 143, pp. 1291-1301.

De Villiers, C., Rouse, P. and Kerr, J. (2016), “A new conceptual model of influences driving sustainability based on case evidence of the integration of corporate sustainability management control and reporting", Special Volume: The Integration of Corporate Sustainability Assessment, Management Accounting, Control, and Reporting, Vol. 136, pp. 78-85.

Delmas, M. and Blass, V.D. (2010), "Measuring corporate environmental performance: the trade-offs of sustainability ratings", Business Strategy and the Environment, Vol. 19, pp. 245-260.

DiMaggio, P. and Powell, W. (1983), "The iron cage revisited: institutional isomorphism and collective rationality in organizational fields", American Sociological Review, Vol. 48, pp. 147-160.

Ditillo, A. and Lisi, I.E. (2014), "Towards a more comprehensive framework for sustainability control systems research", Accounting for the Environment: More Talk and Little Progress, Emerald Group Publishing, Bingley, pp. 23-47.

Donker, H. and Zahir, S. (2008), "Towards an impartial and effective corporate governance rating system”, Corporate Governance: The International Journal of Business in Society, Vol. 8, pp. 83-93.

Drempetic, S., Klein, C. and Zwergel, B. (2019), "The influence of firm size on the ESG score: corporate sustainability ratings under review", Journal of Business Ethics, pp. 1-28.

Durden, C. (2008), "Towards a socially responsible management control system”, Accounting, Auditing and Accountability Journal, Vol. 21, pp. 671-694.

Dutta, S.K., Lawson, R.A. and Marcinko, D.J. (2016), "A management control system to support corporate sustainability strategies", Advances in Accounting, Vol. 32, pp. 10-17.

Eccles, R.G. and Stroehle, J.C. (2018), Exploring Social Origins in the Construction of ESG Measures, SSRN Scholarly Paper No. ID 3212685, Social Science Research Network, Rochester, New York, NY.

Eccles, R.G., Ioannou, I. and Serafeim, G. (2014), "The impact of corporate sustainability on organizational processes and performance", Management Science, Vol. 60, pp. 2835-2857. 
Engert, S., Rauter, R. and Baumgartner, R.J. (2016), "Exploring the integration of corporate sustainability into strategic management: a literature review", Journal of Cleaner Production, Vol. 112, pp. 2833-2850.

Epstein, M.J. (2003), "The identification, measurement, and reporting of corporate social impacts: past, present, and future", Advances in Environmental Accounting and Management, Emerald Group Publishing, Bingley, pp. 1-29.

Epstein, M.J. and Buhovac, A.R. (2014), Making Sustainability Work: Best Practices in Managing and Measuring Corporate Social, Environmental, and Economic Impacts, Berrett-Koehler Publishers, San Francisco.

Evans, S., Vladimirova, D., Holgado, M., Van Fossen, K., Yang, M., Silva, E.A. and Barlow, C.Y. (2017), "Business model innovation for sustainability: towards a unified perspective for creation of sustainable business models", Business Strategy and the Environment, Vol. 26, pp. 597-608.

Fowler, S.J. and Hope, C. (2007), "A critical review of sustainable business indices and their impact", Journal of Business Ethics, Vol. 76, pp. 243-252.

Galpin, T., Whitttington, J.L. and Bell, G. (2015), "Is your sustainability strategy sustainable? Creating a culture of sustainability", Corporate Governance, Vol. 15, pp. 1-17.

García-Sánchez, I.M., Suárez-Fernández, O. and Martínez-Ferrero, J. (2019), "Female directors and impression management in sustainability reporting”, International Business Review, Vol. 28, pp. 359-374.

George, R.A., Siti-Nabiha, A.K., Jalaludin, D. and Abdalla, Y.A. (2016), "Barriers to and enablers of sustainability integration in the performance management systems of an oil and gas company", Special Volume: The Integration of Corporate Sustainability Assessment, Management Accounting, Control, and Reporting, Vol. 136, pp. 197-212.

Gond, J.P., Grubnic, S., Herzig, C. and Moon, J. (2012), "Configuring management control systems: theorizing the integration of strategy and sustainability", Management Accounting Research, Vol. 23, pp. 205-223.

Gonzalez Gonzalez, J.M. and Zamora Ramirez, C. (2016), "Organisational communication on climate change: the influence of the institutional context and the adoption pattern", International Journal of Climate Change Strategies and Management, Vol. 8, pp. 286-316.

Graf, C. and Wirl, F. (2014), "Corporate social responsibility: a strategic and profitable response to entry?”, Journal of Business Economics, Vol. 84, pp. 917-927.

Grant, R.M. (1995), Contemporary Strategy Analysis, Blackwell Business, Cambridge.

Gray, R., Owen, D. and Adams, C. (2009), "Some theories for social accounting?: a review essay and a tentative pedagogic categorisation of theorisations around social accounting", Sustainability, Environmental Performance and Disclosures, Emerald Group Publishing, Bingley, pp. 1-54.

Guenther, E., Endrikat, J. and Guenther, T.W. (2016), "Environmental management control systems: a conceptualization and a review of the empirical evidence", Journal of Cleaner Production, Vol. 136, pp. 147-171.

Gunarathne, N., Samudrage, D., Wijesinghe, D.N. and Lee, K.H. (2016), "Fostering social sustainability management through safety controls and accounting: a stakeholder approach in the mining sector", Accounting Research Journal, Vol. 29, pp. 179-197.

Hansen, E.G. and Schaltegger, S. (2016), "The sustainability balanced scorecard: a systematic review of architectures", Journal of Business Ethics, Vol. 133, pp. 193-221.

Hansen, E.G. and Schaltegger, S. (2017), "Sustainability balanced scorecards and their architectures: irrelevant or misunderstood?", Journal of Business Ethics, Vol. 150, pp. 937-952.

Hart, S.L. (1995), “A natural-resource-based view of the firm”, Academy of Management Review, Vol. 20, pp. 986-1014.

Sustainability

management control tools 
AAAJ 34,9

Herremans, I.M. and Nazari, J.A. (2016), "Sustainability reporting driving forces and management control systems", Journal of Management Accounting Research, Vol. 28, pp. 103-124.

Herremans, I.M., Nazari, J.A. and Ingraham, L. (2010), "Externalities and internalities in sustainability reporting", CAAA Annual Conference, Vancouver.

Herzig, C., Viere, T., Schaltegger, S. and Burritt, R.L. (2012), Environmental Management Accounting: Case Studies of South-East Asian Companies, Routledge, New York, NY.

Hillman, A.J. and Dalziel, T. (2003), "Boards of directors and firm performance: integrating agency and resource dependence perspectives", Academy of Management Review, Vol. 28, pp. 383-396.

Hristov, I., Chirico, A. and Appolloni, A. (2019), "Sustainability value creation, survival, and growth of the company: a critical perspective in the sustainability balanced scorecard (SBSC)", Sustainability, Vol. 11, p. 2119.

Idda, L., Furesi, R., Madau, F.A. and Rubino, C. (2002), "The Italian fishing and aquaculture system in a sustainable development perspective: a multicriterial approach to the theme", 10th EAAE Congress "Exploring diversity in European Agri-food System", Zaragoza, Spain, August 28-31.

Jansen, H. (2010), "The logic of qualitative survey research and its position in the field of social research methods", Forum: Qualitative Sozialforschung/Forum: Qualitative Social Research, Vol. 11, pp. 1-21.

Jenkins, A.M. (1985), "Research methodologies and MIS research", Research Methods: Information, Systems, Vol. 103, p. 117.

Johnstone, L. (2019), "Theorising and conceptualising the sustainability control system for effective sustainability management", Journal of Management Control, Vol. 30, pp. 25-64.

Lackmann, J., Ernstberger, J. and Stich, M. (2012), "Market reactions to increased reliability of sustainability information", Journal of Business Ethics, Vol. 107, pp. 111-128.

Lacy, P., Cooper, T., Hayward, R. and Neuberger, L. (2010), "A new era of sustainability. CEO reflections on progress to date, challenges ahead and the impact of the journey toward a sustainable economy”, UN Global Compact-Accenture.

Lankoski, L. (2016), "Alternative conceptions of sustainability in a business context", Journal of Cleaner Production, Vol. 139, pp. 847-857.

Lassala, C., Apetrei, A. and Sapena, J. (2017), "Sustainability matter and financial performance of companies", Sustainability, Vol. 9, p. 1498.

Laufer, W.S. (2003), "Social accountability and corporate greenwashing", Journal of Business Ethics, Vol. 43, pp. 253-261.

Lemon, M. and Sahota, P.S. (2004), "Organizational culture as a knowledge repository for increased innovative capacity”, Technovation, Vol. 24, pp. 483-498.

Leung, L. (2015), "Validity, reliability, and generalizability in qualitative research", Journal of Family Medicine and Primary Care, Vol. 4, pp. 324-327.

Lueg, R. and Radlach, R. (2016), "Managing sustainable development with management control systems: a literature review”, European Management Journal, Vol. 34, pp. 158-171.

Lyon, T.P. and Maxwell, J.W. (2011), "Greenwash: corporate environmental disclosure under threat of audit", Journal of Economics and Management Strategy, Vol. 20, pp. 3-41.

Maas, K., Schaltegger, S. and Crutzen, N. (2016a), "Integrating corporate sustainability assessment, management accounting, control, and reporting", Journal of Cleaner Production, Vol. 136, pp. 237-248.

Maas, K., Schaltegger, S. and Crutzen, N. (2016b), "Advancing the integration of corporate sustainability measurement, management and reporting", Journal of Cleaner Production, Vol. 133, pp. 859-862.

Malmi, T. and Brown, D.A. (2008), "Management control systems as a package-opportunities, challenges and research directions", Management Accounting Research, Management Control Systems as a Package, Vol. 19, pp. 287-300. 
Merchant, K.A. (1985), Control in Business Organization, Pitman, Boston.

Morioka, S.N. and de Carvalho, M.M. (2016), "A systematic literature review towards a conceptual framework for integrating sustainability performance into business", Special Volume: The Integration of Corporate Sustainability Assessment, Management Accounting, Control, and Reporting, Vol. 136, pp. 134-146.

Morsing, M. and Oswald, D. (2009), "Sustainable leadership: management control systems and organizational culture in Novo Nordisk A/S", Corporate Governance International Journal of Business in Society, Vol. 9, pp. 83-99.

Munda, G., Nijkamp, P. and Rietveld, P. (1994), "Qualitative multicriteria evaluation for environmental management”, Ecological Economics, Vol. 10, pp. 97-112.

Nijkamp, P. and Vindigni, G. (1999), "Integrated multicriteria analysis for sustainable agricultural policy evaluation", Rivista di Economia Agraria, Vol. 53, pp. 9-40.

Nijkamp, P., Rietveld, P. and Voogd, H. (1990), Multiple Criteria Analysis in Physical Planning, Elsevier, Amsterdam, North Holland.

Norris, G. and O'Dwyer, B. (2004), "Motivating socially responsive decision making: the operation of management controls in a socially responsive organisation", The British Accounting Review, Vol. 36, pp. 173-196.

Orsato, R.J., Garcia, A., Mendes-Da-Silva, W., Simonetti, R. and Monzoni, M. (2015), "Sustainability indexes: why join in? A study of the 'Corporate Sustainability Index (ISE)'in Brazil”, Journal of Cleaner Production, Vol. 96, pp. 161-170.

Ouchi, W.G. (1979), "A conceptual framework for the design of organizational control mechanisms", Management Science, Vol. 25, pp. 813-930.

Perego, P. and Hartmann, F. (2009), "Aligning performance measurement systems with strategy: the case of environmental strategy", Abacus, Vol. 45, pp. 397-428.

Pondeville, S., Swaen, V. and De Rongé, Y. (2013), "Environmental management control systems: the role of contextual and strategic factors", Management Accounting Research, Vol. 24, pp. 317-332.

Riccaboni, A. and Leone, E.L. (2010), "Implementing strategies through management control systems: the case of sustainability", International Journal of Productivity and Performance Management, Vol. 59, pp. 130-144.

Rodríguez-Olalla, A. and Avilés-Palacios, C. (2017), "Integrating sustainability in organisations: an activity-based sustainability model”, Sustainability, Vol. 9, p. 1072.

Rokeach, M. (1973), The Nature of Human Values, Free press, New York, NY.

Ruhnke, K. and Gabriel, A. (2013), "Determinants of voluntary assurance on sustainability reports: an empirical analysis", Journal of Business Economics, Vol. 83, pp. 1063-1091.

Rusconi, G. (2019), "Ethical firm system and stakeholder management theories: a possible convergence", European Management Review, Vol. 16, pp. 147-166.

Russo, M.V. and Fouts, P.A. (1997), "A resource-based perspective on corporate environmental performance and profitability", Academy of Management Journal, Vol. 40, pp. 534-559.

Saviano, M., Di Nauta, P., Montella, M.M. and Sciarelli, F. (2018), "The cultural value of protected areas as models of sustainable development", Sustainability, Vol. 10, p. 1567.

Schaltegger, S. and Burritt, r. (2010), "Sustainability accounting for companies: catchphrase or decision support for business leaders?", Journal of World Business, Vol. 45, pp. 375-384.

Schaltegger, S. and Hörisch, J. (2017), "In search of the dominant rationale in sustainability management: legitimacy- or profit-seeking?”, Journal of Business Ethics, Vol. 145, pp. 259-276.

Schaltegger, S. and Wagner, M. (2006), "Integrative management of sustainability performance, measurement and reporting", International Journal of Accounting, Auditing and Performance Evaluation, Vol. 3, pp. 1-19. 
Schulze, M., Nuhn, H. and Gleich, R. (2012), "Sustainability performance measurement", Nachhaltigkeits Controlling, Haufe, Freiburg, pp. 91-111.

Seeger, M.W. (2006), "Best practices in crisis communication: an expert panel process", Journal of Applied Communication Research, Vol. 34, pp. 232-244.

Simons, R. (1995), Levers of Control, Harvard Business School Press, Boston MA.

Stekelenburg, A., Georgakopoulos, G., Sotiropoulou, V., Vasileiou, K. and Vlachos, I. (2015), “The relation between sustainability performance and stock market returns: an empirical analysis of the Dow Jones sustainability Index Europe", International Journal of Economics and Finance, Vol. 7, pp. 74-88.

Sundin, H. and Brown, D.A. (2017), "Greening the black box: integrating the environment and management control systems", Accounting, Auditing and Accountability Journal, Vol. 30, pp. $620-642$.

Teece, D.J., Pisano, G. and Shuen, A. (1997), "Dynamic capabilities and strategic management", Strategic Management Journal, Vol. 18, pp. 509-533.

UN Global Compact (2020), Using Bus. Better Word, URL, available at: https://www.unglobalcompact. org/sdgs/about.

Vitale, G., Cupertino, S., Rinaldi, L. and Riccaboni, A. (2019), "Integrated management approach towards sustainability: an Egyptian business case study", Sustainability, Vol. 11, p. 1244.

Wasner, I. and Majchrzak, T.A. (2015), "Sustainability management control practice: a study of German SMEs", Presented at the System Sciences (HICSS), 2015 48th Hawaii International Conference on, IEEE, Hawaii, pp. 876-885.

Wijen, F. (2014), "Means versus ends in opaque institutional fields: trading off compliance and achievement in sustainability standard adoption", Academy of Management Review, Vol. 39, pp. 302-323.

Wijethilake, C. and Ekanayake, A. (2018), "Proactive strategic responses to corporate sustainability pressures: a sustainability control system framework", Advances in Management Accounting, Vol. 30, pp. 129-173.

Wijethilake, C., Wijethilake, C., Munir, R., Munir, R., Appuhami, R. and Appuhami, R. (2017), "Strategic responses to institutional pressures for sustainability: the role of management control systems", Accounting, Auditing and Accountability Journal, Vol. 30, pp. 1677-1710.

Windolph, S.E. (2011), "Assessing corporate sustainability through ratings: challenges and their causes”, J. Environ. Sustain., Vol. 1, pp. 61-80.

Windolph, S.E., Schaltegger, S. and Herzig, C. (2014), "Implementing corporate sustainability. What drives the application of sustainability management tools in Germany?”, Motive Organization Units Management Tools Tak. Stock Why Who Implement.Corp., Sustainable Management, Vol. 5, pp. 378-404.

\section{Appendix}

The construction of the impact matrix requires the assignment of the behaviour indices $\left(p_{i j}\right)$ of each alternative (dimensions of the object) with respect to each criterion (companies interviewed). The $p_{i j}$ represents the impact that alternative $i$ has on criterion $j$ (i.e. the judgements of all societies on the importance they give to all dimensions of the object). In this case, we adopted a five-point judgement scale from 1 (very low) to 5 (very high).

Constructing the behaviour indices $\left(p_{i j}\right)$ first requires identifying the parameters (referable, in our framework, to the categories of dimensions) for all three dimensions explaining the companies' behaviour. Specifically, "background in sustainability" (D1) and "company's division dedicated to sustainability" (D2) include five parameters, which assign (for each company) a judgement of 0 or 1, depending on compliance or not with the parameter, while the "sustainability management control tools" dimension (D3) includes ten parameters, which can involve a judgement of 0 or 0.5 . 
Secondly, the sum of the parameters (which can be, at most, five dimensions for each company) is made for each company and its dimensions. Since the methodology requires the use of discrete values, the judgements obtained are rounded upwards. This sum represents the $p_{i j}$ indices reported in the impact matrix and describes the results of the evaluation of the impact each dimension has on each company.

The regime matrix is constructed starting from the evaluations contained in the impact matrix, which are used to establish a relative order of preference among the alternatives under examination. Its construction takes place in the course of a pairwise comparison of the $\left(p_{i j}\right)$ indices. The elements of the impact matrix are composed by

$$
\begin{aligned}
& a_{i i^{\prime}, j}=+1 \text { if } p_{i j}>p_{i i^{\prime} j} \\
& a_{i i^{\prime}, j}=-1 \text { if } p_{i j}<p_{i i^{\prime} j} \\
& a_{i i^{\prime}, j}=0 \text { if } p_{i j}=p_{i i^{\prime} j}
\end{aligned}
$$

where $a_{i i^{i}, j}$ expresses the difference between the behaviour indices ( $p_{i j}$ and $p_{i i j}$ ) among alternatives $i$ and $i$ for criterion $j$. Since the comparison concerns an ordinal variable, the order of magnitude of the difference between the two alternatives is not relevant, and only the sign is considered. In the matrix regime, each line represents the regime vector, which expresses the degree of dominance of alternative $i$ on alternative $i^{\prime}$. If the regime vector contains only positive signs, alternative $i$ is preferred over alternative $i^{\prime}$. In general, however, the regime vector is not composed solely of a series of values with the same sign; otherwise, it is not possible to unambiguously establish the preferability of one alternative over another.

Afterwards, we attribute weights to the criteria $\left(\lambda_{j}\right)$ in order to reflect their relative importance. In our analysis, the evaluation of the importance of each criterion (companies) concerns the weighted number of indices (maximum of five) in which each company is included.

To obtain the alternative rankings, first it is necessary, for each comparison, to construct the $c_{i i}$ index. This expresses a measure of preferability between two alternatives examined from time to time. It is obtained by the sum of the weighted regime vector elements $a_{i i^{\prime}, j}$ corresponding to the weights of the related criteria $\left(\lambda_{j}\right)$, according to the formula

$$
c_{i i^{\prime}}=\sum_{j=1}^{j} \lambda_{j} \cdot a_{i i^{\prime}, j}
$$

where if $c_{i i^{\prime}}>0$, alternative $i$ is preferred over alternative $i$.

The $c_{i^{\prime}}$ index expresses the priority between only two alternatives, but does not provide information about the order of preferences among all alternatives. Therefore, the last phase seeks to obtain the ranking of all alternatives and the selection of the "best" one, which in our analysis refers to the dimension of the object to which the companies pay the most attention. The aggregate priority of each alternative, when considering all the criteria adopted, is expressed by the $C_{i}$ value

$$
C_{i}=\frac{\sum_{i^{\prime}}^{n-1} c_{i i^{\prime}} \cdot j}{n-1}
$$

$C_{i}$ is conveniently normalised to be included between 0 and +1 . The alternative that reports the highest final value is the most engaging one, according to the criteria set adopted. 


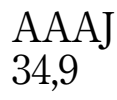

\begin{tabular}{ll} 
Dimensions & Categories \\
\hline $\begin{array}{l}\text { Background in } \\
\text { sustainability }\end{array}$ & $\begin{array}{l}\text { Current disclosure on } \\
\text { sustainability (i.e. Sustainability } \\
\text { report, Directive 2014/95/EU, }\end{array}$
\end{tabular}

Criteria

Behaviour

Integrated report)

54

Number of years of sustainability

disclosure

Use of GRI standards

Only one type

More than one type

indices

Activation of sustainability training projects (in the past, now, in the future)

Number of certifications, principles and standards used*

Company's

Name of department

$\leq 3$

$>3$

Used

Not used

At least in two periods

Only in a period

1

department dedicated

to sustainability

$\geq 4$

$<4$

Reference to CSR or

Sustainability

Reference to external

relations

Number of members

$$
\leq 5
$$

Chain of command

$>5$

Related to external

communication

Related to the administrative department

Resources' involvement level $\geq 5$

(human, technical and informatics) $\quad<5$

Number of professionals included

Table A1. 


\begin{tabular}{|c|c|c|c|c|}
\hline Dimensions & Categories & Criteria & $\begin{array}{l}\text { Behaviour } \\
\text { indices }\end{array}$ & Sustainability \\
\hline $\begin{array}{l}\text { Sustainability } \\
\text { management control } \\
\text { tools }\end{array}$ & $\begin{array}{l}\text { SMCTs' effectiveness in employees } \\
\text { behaviours' alignment } \\
\text { In the whole. the effectiveness of } \\
\text { the SMCTs to lead the company } \\
\left(E_{w}\right) \\
\text { Constraints linked to SMCTs **** } \\
\text { Gap between desired and current } \\
\text { use of SMCTs }\left(G_{f}\right) \\
\text { Gap between effectiveness } \\
\text { assigned and achieved by SMCTs } \\
\left(G_{f} \%\right)^{* * * * * *} \\
\text { Level of cognitive. technical and } \\
\text { organisational integration }\end{array}$ & $\begin{array}{l}\text { Hight knowledge of } \geq 7 \text { tools } \\
\text { Hight knowledge of }<7 \text { tools } \\
\geq 7 \\
<7 \\
\geq 50 \% \text { of those implemented } \\
\text { are used both diagnostically } \\
\text { and interactively } \\
<50 \% \text { of those implemented } \\
\text { are used both diagnostically } \\
\text { and interactively } \\
\geq 4 \\
<4 \\
\geq 5 \\
<5 \\
\geq 5 \\
<5\end{array}$ & $\begin{array}{l}0.5 \\
0 \\
0.5 \\
0 \\
0.5 \\
0\end{array}$ & 55 \\
\hline \multicolumn{5}{|c|}{ 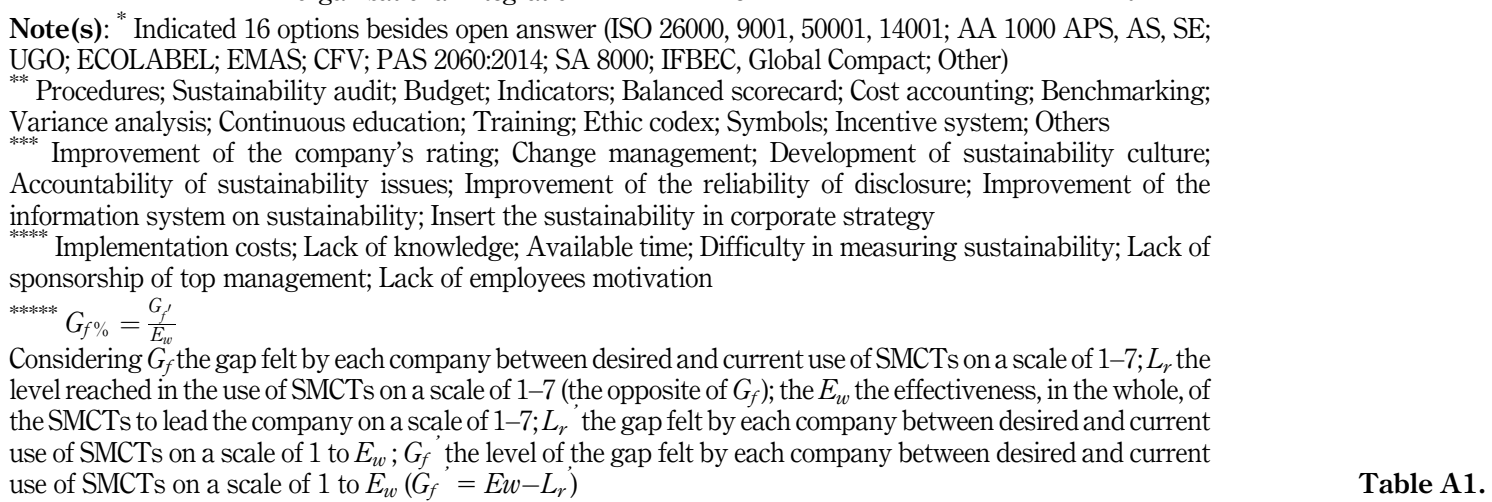 } \\
\hline
\end{tabular}


AAAJ

34,9

56

Comparison Criteria

between

\begin{tabular}{llllllllllllllllllllll}
\hline D1-D2 & 1 & 1 & 0 & -1 & 1 & -1 & 0 & 1 & 0 & 1 & 1 & 1 & & & & & & & & &
\end{tabular}

\begin{tabular}{lllllllllllllllllllll} 
D1-D2 & 1 & 1 & 0 & -1 & 1 & -1 & 0 & 1 & 0 & 1 & 1 & 1 & 1 & 0 & 1 & 1 & 1 & 0 & 1 & 1 \\
\hline & 1 & 1 & -1 & -1 & 1 & -1 & 1 & 1 & 1 & 1 & 1 & 1 & -1 & -1 & 0 & 1 & 1 & 1 & -1 & 1
\end{tabular}

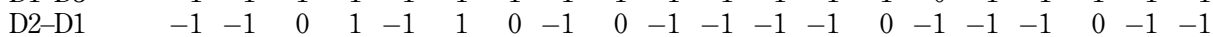

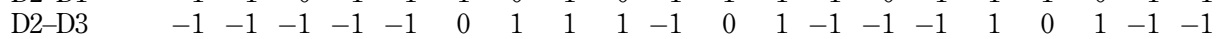

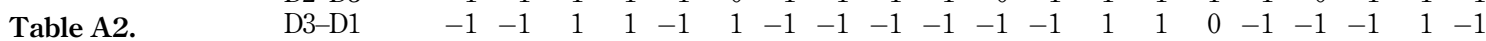

$\begin{array}{lllllllllllllllllllllllll}\text { Regime matrix } & \text { D3-D2 } & 1 & 1 & 1 & 1 & 1 & 0 & -1 & -1 & -1 & 1 & 0 & -1 & 1 & 1 & 1 & -1 & 0 & -1 & 1 & 1\end{array}$

Table A3.

Priorities of judgement

criteria

\begin{tabular}{lcccccccccccccccccccc} 
Criteria & 1 & 2 & 3 & 4 & 5 & 6 & 7 & 8 & 9 & 10 & 11 & 12 & 13 & 14 & 15 & 16 & 17 & 18 & 19 & 20 \\
\hline Weight (0/ & 29 & 5.7 & 11.4 & 29 & 29 & 29 & 29 & 11.4 & 29 & 8.6 & 86 & 29 & 29 & 29 & 5.7 & 29 & 5.7 & 5.7 & 29 & 5.7
\end{tabular}

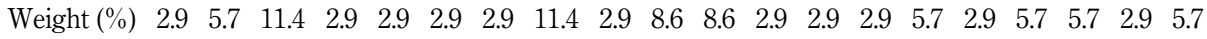

Table A4.

Preference among

alternatives $\left(c_{i^{\prime}}\right)$

\begin{tabular}{lcccccc}
\hline Alternatives & D1-D2 & D1-D3 & D2-D1 & D2-D3 & D3-D1 & D3-D2 \\
\hline$c_{i i}$ & 0.629 & 0.429 & -0.629 & -0.257 & -0.429 & 0.257 \\
\hline
\end{tabular}

\section{Corresponding author}

Brunella Arru can be contacted at: brarru@uniss.it

For instructions on how to order reprints of this article, please visit our website:

www.emeraldgrouppublishing.com/licensing/reprints.htm

Or contact us for further details: permissions@emeraldinsight.com 